\title{
The efficacy of a 10\% aqueous Neem (Azadirachta indica) seed extract for tick control in Small East African and Toggenburg female goat kids in Tanzania
}

\author{
L.M.J. Schwalbach $\#$, J.P.C. Greyling and M. David \\ Department of Animal, Wildlife \& Grassland Sciences, University of the Free State, P.O. Box 339, Bloemfontein 9300, \\ South Africa
}

\begin{abstract}
The aim of this experiment was to evaluate the efficacy of Neem seed extract (10\% water solution) for tick control in goats in the Kilimanjaro area of Tanzania. Eighteen Small East African (SEA) and Toggenburg (TB) female goat kids between 2.5 and 4 months of age were used in the trial. Goats were divided into two similar groups according to age, body weight and breed composition. Ten treated kids $(\mathrm{n}=$ 6 SEA and $n=4$ TB goats) and eight controls $(n=4$ SEA and $n=4$ TB goats) were housed in separate pens for shelter at night, but grazed/browsed together during the day on natural pastures infested with adult and immature ticks. The Neem-treated group was hand sprayed weekly (spot treatment) with a $10 \%$ aqueous solution of Neem seed extract to the following regions: perineum, udder, ears and sternum at a rate of 10 $\mathrm{mL} / \mathrm{kg}$ body weight. The control animals were sprayed weekly with water $(10 \mathrm{~mL} / \mathrm{kg}$ body weight) to the same sites. Neem-treated goat kids recorded significantly lower tick numbers than the control animals, with significantly lower tick numbers and tick bite abscesses in the indigenous SEA goats compared to the goats of the exotic TB breed. Significantly higher tick infestations were recorded on both breeds of goats during the summer rainy season. It was concluded that Neem seed extract is effective in controlling ticks in goats. Further studies are necessary to fully understand the effect of Neem on ticks.
\end{abstract}

Keywords: Ticks, goats, Neem seed extract

${ }^{\#}$ Corresponding author. E-mail: Schwallm@sci.uovs.ac.za

\section{Introduction}

Ticks and tick-borne diseases (TBD) are major limitations to livestock production including goats in southern Africa (Penzhorn \& Krecek, 1997). The local environmental conditions (temperature, humidity, type of vegetation) and the abundance of wildlife that are reservoirs for these parasites create ideal conditions for tick proliferation and survival.

Ticks may have direct effects on animals (as blood sucking parasites), causing anaemia, weight loss, damage to skins and hides and indirect effects when they transmit highly pathogenic viruses, rickettsias and protozoa. These micro-organisms cause important TBD, endemic to most of southern Africa, and particularly to Tanzania resulting in high mortality rates in large and small stock (de Castro 1987; Norval et al., 1988). Ticks are also largely responsible for damages that affect the quality of skins as well as damage to the teats and testes of animals (Rocha et al., 1990; Mersie \& Bekele, 1994). The approach for TBD control in southern Africa is centred on intensive vector control for tick eradication (FAO, 1987) using insecticides (chemical control). This approach has had limited success and lack of sustainability (poor efficiency, poor adoption rate by the local traditional small-scale resource poor farmers, etc.) (de Castro, 1997). The indiscriminate use of acaricides in southern Africa has lead to the development of resistance, environmental contamination and limited success in the control of ticks and TBD (de Castro, 1997; Ameen, 2001). A new approach is thus necessary for the control of these parasites and the diseases that they transmit to livestock. This includes the use of indigenous livestock in southern Africa that are relatively resilient to ticks and TBD (Norval et al, 1988), and the strategic use of acaricides as part of integrated management systems based on holistic and sustainable management practices.

There is a need to develop alternative and effective organic pesticides preferably from locally available resources, which are more cost-effective than the currently chemically produced insecticides. This would result in a more sustainable livestock production in southern Africa. Azadirachta indica or Neem tree belongs to the family Meliacea and is distributed widely in Asia, Africa and other tropical parts of the world (Webb \& David, 2002). It has been proven that several parts of the Neem tree have active components with a repellent action on many crop insect pests (Zebitz, 1986; Schumutterer, 1990). However, very little is known about the efficacy of Neem components for tick control in livestock. In a recent report (Webb \& David, 
2002) the potential use of Neem seed extracts for tick control in cattle, particularly in the case of small-scale resource poor farmers, was recognised.

The objectives of the present trial were: (i) to evaluate the efficiency of a $10 \%$ aqueous extract of Neem seed used as a spot treatment for tick control in goat kids in Tanzania and (ii) to compare the breed susceptibility of the indigenous Small East African goat and the Toggenburg goat, which is exotic to Tanzania.

\section{Materials and methods}

The study was conducted in the Kilimanjaro area of Tanzania, located between latitude $2^{\circ} 50^{\prime}$ and $3^{\circ}$ $10^{\prime} \mathrm{S}$, longitude $37^{\circ} 10^{\prime}$ and $37^{\circ} 40^{\prime} \mathrm{E}$ and at an altitude of $1800 \mathrm{~m}$ above sea level. It lasted one year and covered autumn-winter (April to August), spring (September and October) and summer (November to March). The study area receives between 1500 and $2000 \mathrm{~mm}$ of rain per year. Eighteen Small East African (SEA) and Toggenburg (TB) female goat kids between 2.5 - 4 months of age were used in this trial. Goats were divided into two similar groups according to age, body weight and breed composition. Ten treated kids $(n=6$ SEA and $n=4$ TB) goats and eight controls $(n=4$ SEA and $n=4$ TB) goats were housed in separate pens for shelter at night, but grazed/browsed together during the day on a natural pasture known to be infested with ticks. The treated group was hand sprayed weekly (spot treatment) with a $10 \%$ solution of an aqueous Neem seed extract in the following regions: perineum, udder, ears and sternum at a rate of $10 \mathrm{~mL} / \mathrm{kg}$ body weight. The full procedure to prepare the $10 \%(\mathrm{w} / \mathrm{v})$ aqueous Neem seed extract was described by Matayo (2002). In short, the solution was prepared by dissolving in $10 \mathrm{~L}$ of cold water, one $\mathrm{kg}$ of the fine powder (crushed with a wooden mortar and pestle) sun-dried seeds collected from ripe fruits.

The control animals were sprayed with water at the same rate of $10 \mathrm{~mL} / \mathrm{kg}$ body weight in the same anatomical regions as described for the treated group. Before each weekly treatment both treated and control animals were restrained by an assistant and examined for the presence of visible adult ticks at different stages of engorgement. All visible ticks were collected from the goats for later identification and quantification in the laboratory. They were removed with the aid of forceps and placed in labelled plastic containers filled with $70 \%$ ethanol. During tick collection the animals were also carefully examined for the presence of abscesses. The herdsman was instructed to inspect the animals on a daily basis for the presence of abscesses and record occurrences. This was done to evaluate the tolerance of the animals to tick infestation. Data were statistically analysed by Analysis of Variance (ANOVA), using the General Linear Model (GLM) procedures for repeated measure analysis of SAS (1992). The main factors considered in the model were Neem treatment, goat breed and season of the year.

\section{Results and discussion}

The results of the multi-factorial ANOVA showed that the mean total tick counts (per species and in total) were significantly $(\mathrm{P}<0.01)$ influenced by: the Neem treatment, the goat breed and the season in which the counts were made. None of the interactions considered (treatment $\mathrm{x}$ breed and season $\mathrm{x}$ treatment) was significant (Table 1).

Table 1 The effect of Neem treatment, goat breed, season of the year and its interactions on tick counts of goat kids (P-values, based on the multi-factorial analysis of variance - ANOVA)

\begin{tabular}{lcccc}
\hline Variable & $\begin{array}{c}\text { Amblyomma } \\
\text { hebraeum }\end{array}$ & $\begin{array}{c}\text { Hyalomma } \\
\text { truncatum }\end{array}$ & $\begin{array}{c}\text { Rhipicephalus } \\
\text { evertsi }\end{array}$ & Total tick count \\
\hline Neem treatment & 0.0001 & 0.0001 & 0.0249 & 0.0001 \\
Goat breed & 0.0001 & 0.0001 & 0.0045 & 0.0001 \\
Treatment x Breed & $0.3452^{*}$ & $0.7031^{*}$ & $0.2321^{*}$ & $0.2256^{*}$ \\
Season & 0.0001 & 0.0001 & 0.0001 & 0.0001 \\
Season x Treatment & $0.0916^{*}$ & $0.7732^{*}$ & $0.6341^{*}$ & $0.8646^{*}$ \\
\hline
\end{tabular}

* Not significant.

Neem treated goat kids showed a reduction $(\mathrm{P}<0.01)$ in tick numbers in contrast to the control animals. As has been described by other authors, there was a seasonal fluctuation in tick burdens. Higher ( $\mathrm{P}<$ 0.01 ) tick counts were recorded on both breeds of goats during the rainy season (summer), but throughout the 
trial period the indigenous SEA goats showed lower $(\mathrm{P}<0.01)$ tick infestations than the exotic TB goats. These differences were more evident during the summer months when tick infestations were significantly higher $(\mathrm{P}<0.01)$. Higher tick counts were obtained during summer presumably due to the fact that the eggs hatch and ticks breed during the rainy season when the ambient temperature and humidity are higher and more conducive to the proliferation of these parasites. This is in agreement with Spickett et al. (1989) who found that during the summer months tick populations increase more rapidly, resulting in an upsurge of tick infestations on goats and other farm animals. A lower $(\mathrm{P}<0.01)$ number of ticks was observed in both breeds during the dry and winter season of the year. The differences observed for the total number of ticks counted, were also observed for each tick species (Amblyomma hebraeum, Hyalomma truncatum and Rhipicephalus evertsi) (Table 2).

Table 2 Mean $( \pm \mathrm{SD})$ tick counts (total and per species) in Small East African (SEA) and Toggenburg (TB) goat kids treated with a $10 \%$ Neem seed extract $v$ s. untreated kids

\begin{tabular}{|c|c|c|c|c|}
\hline \multirow{2}{*}{$\begin{array}{l}\text { Treatment group } \\
\text { Breed and number of kids }\end{array}$} & \multicolumn{2}{|c|}{$10 \%$ Neem } & \multicolumn{2}{|c|}{ Control } \\
\hline & $\begin{array}{c}\text { SEA } \\
n=6\end{array}$ & $\begin{array}{c}\mathrm{TB} \\
\mathrm{n}=4\end{array}$ & $\begin{array}{l}\text { SEA } \\
\mathrm{n}=4\end{array}$ & $\begin{array}{c}\text { TB } \\
n=4\end{array}$ \\
\hline Total tick count & & & & \\
\hline Winter & $2.7^{\mathrm{a}} \pm 1$ & $16.8^{\mathrm{b}} \pm 5$ & $37.0^{\mathrm{c}} \pm 1$ & $51.5^{\mathrm{d}} \pm 16$ \\
\hline Spring & $4.3^{\mathrm{a}} \pm 2$ & $25.6^{\mathrm{b}} \pm 4$ & $26.5^{\mathrm{c}} \pm 2$ & $53.5^{\mathrm{d}} \pm 8$ \\
\hline Summer & $13.2^{\mathrm{a}} \pm 8$ & $38.0^{\mathrm{b}} \pm 9$ & $79.3^{\mathrm{c}} \pm 3$ & $138.8^{\mathrm{d}} \pm 36$ \\
\hline Tick count per species & & & & \\
\hline A. hebraeum & $6.3^{\mathrm{a}} \pm 4$ & $17.6^{\mathrm{b}} \pm 3$ & $46.5^{\mathrm{c}} \pm 13$ & $72.5^{\mathrm{d}} \pm 24$ \\
\hline H. truncatum & $4.8^{\mathrm{a}} \pm 4$ & $27.3^{\mathrm{b}} \pm 7$ & $39.3^{c} \pm 18$ & $79.3^{\mathrm{d}} \pm 19$ \\
\hline R. evertsi & $9.0^{\mathrm{a}} \pm 5$ & $35.0^{\mathrm{b}} \pm 9$ & $57.0^{c} \pm 27$ & $92.0^{\mathrm{d}} \pm 18$ \\
\hline Total & $20.2^{\mathrm{a}} \pm 10$ & $80.0^{\mathrm{b}} \pm 15$ & $142.8^{\mathrm{c}} \pm 53$ & $243.8^{\mathrm{d}} \pm 55$ \\
\hline
\end{tabular}

a,b,c,d Means with different superscripts within rows differ significantly $(\mathrm{P}<0.01)$

When the tick counts declined (i.e. in winter) the differences between the two goat breeds tended to be smaller, although still significant $(\mathrm{P}<0.01)$. The fact that all kids grazed together and were equally exposed to a highly infested pasture suggested that both breeds of goats had equal chances of being naturally infested by ticks. These results clearly showed the higher tick resistance of the indigenous SEA goats compared to the exotic TB goats. Tick counts on both breeds were also significantly lower in the Neemtreated group compared to the control animals. This indicates that Neem seed extract had some activity (lethal or repellent) on the various tick species found in the area, namely: A. hebraeum, H. truncatum and $R$. evertsi. These results are in line with those reported by Webb \& David (2002) who also showed a significant reduction in the numbers of the same tick species and on those of Boophilus decoloratus in cattle treated with a 5\% water solution of Neem seed extract. Jotwarni \& Sirca, (1965) and Butterworth \& Morgan (1971) also found that Neem extracts have certain effects on ticks, i.e. insect repelling properties and poor development and growth in parasites, resulting in a reduction of parasite infestation. The Neem seed extract also disrupts mating and oviposition of exposed insects, and inhibits the hatchability of their eggs and failure to moult (Rembold et al., 1986; Saxena, 1993).

Tick counts recorded during the spring season suggest that $R$. appendiculatus ticks were present in lower numbers on both breeds during this period of the year. The peak numbers of H. truncatum ticks were recorded in March (end of summer) and October (mid-spring).

The mean monthly number of observed ruptured abscesses caused by ticks per breed of goat for the duration of the trial period are presented in Figure 1. Most abscesses occurred between the months of December and January (rainy season) when tick counts were the highest. More $(\mathrm{P}<0.05)$ abscesses were recorded on the Toggenburg kids compared to the number of abscesses on the indigenous (SEA) goat kids. Most $(\mathrm{P}<0.05)$ abscesses were observed on the control animals. The incidence of abscesses was attributed to Amblyomma spp., which attaches mainly on body regions such as the udder, perineum (base of the tail and vulva lips) and inter-digital spaces, where most abscesses were observed. During the rainy season some animals were affected by blowfly larvae (Chrysomyia spp.) infection due to abscesses occurring in the 
regions of tick attachment, particularly those of the A. hebraeum. According to Norval (1994) this tick species has a long mouth-part and is frequently responsible for abscesses in livestock, often causing lameness in goats.

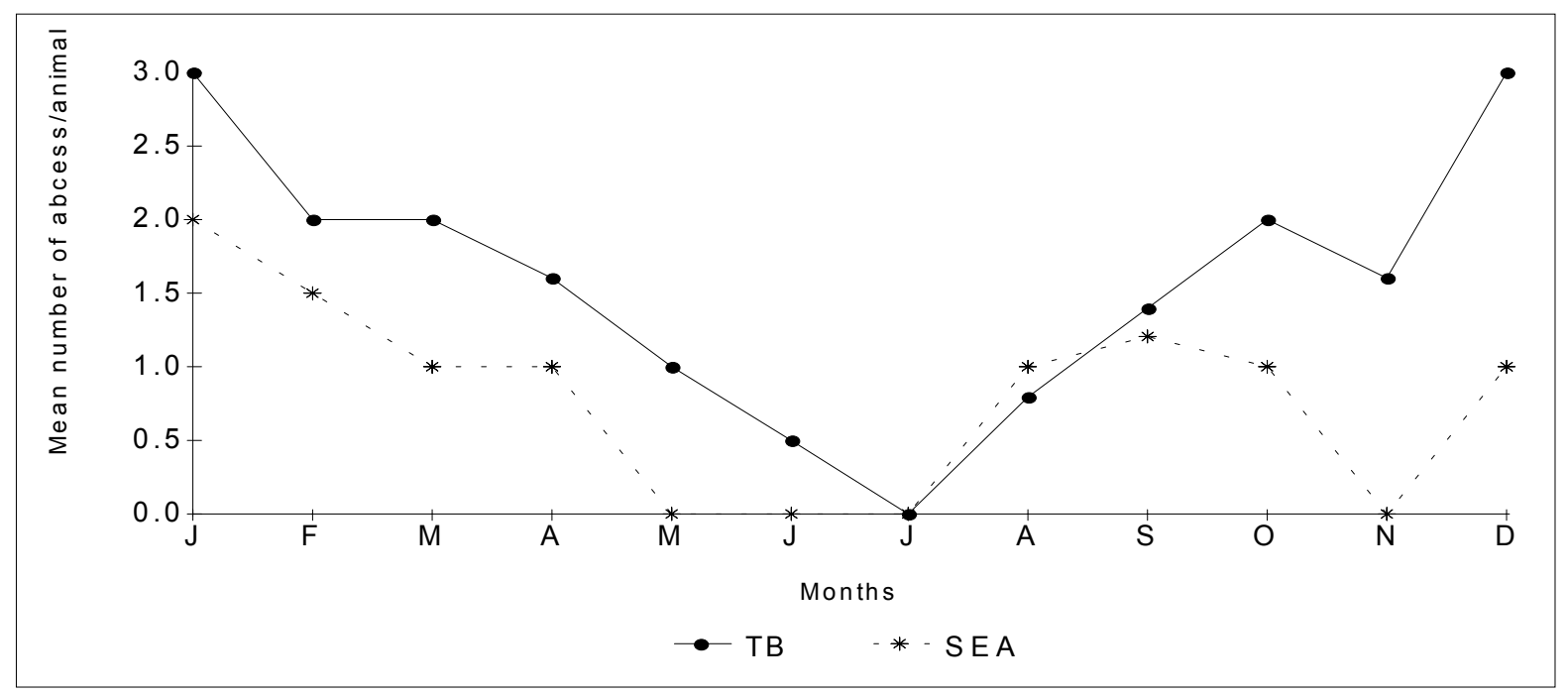

Figure 1 Mean monthly number of tick induced abscesses recorded on Toggenburg (TB) and Small East African (SEA) kids throughout the year

The lower numbers of abscesses observed in the indigenous SEA goats compared to the exotic TB goats are probably a result of higher natural resistance against ticks (lower infestation) and higher tolerance to ticks (less pathogenic consequences of tick infestation). The tick counts on naturally infested goats over a one-year period clearly showed that indigenous SEA goat kids harbour significantly less ticks during periods of tick abundance than the exotic TB goats. Spickett et al. (1989) claimed that the keeping of indigenous breeds that possess a high resistance to tick infestation might be a solution in the undeveloped parts of Africa to the dilemma of tick infestation, TBD and the need for frequent dipping.

A weekly application of a water based solution of $10 \%$ Neem seed extract (10 mL/kg body weight), sprayed on the anatomical areas of the animal preferred by ticks can be successfully used to control ticks in goat kids. This is a cheap, natural and locally available (southern Africa) product with certain properties against ticks and other insects. Its mode of action is not yet fully understood, but it can play a significant role in reducing the indiscriminate use of synthetic chemicals used for external parasite control in livestock. Such chemicals are expensive and potentially dangerous (toxic) to man and the ecosystem. Neem products are reportedly safe to man, non-target organisms and exhibit a reasonable degree of selectivity (Gaitonde \& Seth, 1958; Larson, 1986; Ngomuo \& Kassuku, 1995). This means that Neem seed extract can be used with fewer ecological side-effects than currently used synthetic insecticides. In fact, concentrations of up to $8.5 \mathrm{~g}$ Neem extract/kg body weight have been reported to be non-toxic to rats when applied orally for long periods of time (Schumutterer, 1984).

\section{Conclusions}

The weekly application (spot treatment) of a 10\% solution of an aqueous Neem seed extract sprayed on the anatomical areas preferred by ticks (perineum, udder, ears and sternum) is effective for tick control in goats. This is a cheap natural product with acaricide and/or tick repellent properties that can play a significant role in reducing the use of synthetic insecticides which are potentially dangerous to man and the environment. Neem seed extract is potentially useful for tick control in goats and is of extreme importance for the small-scale resource poor livestock farmers in southern Africa.

It is also concluded that the indigenous Small East African goat breed is more tick resistant than the exotic Toggenburg breed, which also appears to be more susceptible to the development of tick bite abscesses. The use of local breeds (i.e. Small East African goat) is justified in heavily tick-infested areas. This is because they possess a high resistance to tick infestation and higher tolerance to infestation effects 
than the exotic breeds. The use of indigenous goats could be combined with the strategic use of acaricides for tick control. The results of this and other studies on Neem extracts warrant further research on the anti-insect properties of Neem, a natural, cheap and locally available product. This plant offers great potential for the development of much needed new and natural acaricides to counteract the increasing tick resistance to most of the synthetic drugs currently available to the livestock industry.

\section{Acknowledgement}

The authors would like to thank the goat farmers around Kilimanjaro for allowing the use of their animals and M. Fair, University of the Free State, for his assistance with the statistical analyses.

\section{References}

Ameen, M., 2001. Use of ectoparasiticides and resistance. Livest. Health Prod. Rev. 3, 9-10.

Butterworth, J.H. \& Morgan, E.D., 1971. Investigation of the locust feeding inhibition of the seeds of Neem tree (Azadirachta indica). J. Physiol. 17, 969-977.

de Castro, J.J., 1987. Effects of field tick infestation on Borana (Bos indicus) cattle with differing previous exposure to ticks. Proc. Annual Meeting, Australian Centre for International Agricultural Research (ACIAR). 17, 118 (Abstr.).

de Castro, J.J., 1997. Sustainable tick and tick born disease control in livestock improvement in developing countries. Vet. Parasitol. 71, 77-97.

FAO, 1987. The eradication of ticks. Proc. Expert Consultation on the eradication of ticks with special reference to Latin America, 22-26 June, 1987. Mexico City. FAO Animal Production and Health Paper $75,322 \mathrm{pp}$.

Gaitonde, B.B. \& Seth, U.K., 1958. Pharmacological studies of sodium nimbidinate. Ind. J. Med. Res. 13, 156-161.

Jotwarni, M.G. \& Sirca, P., 1965. Neem seed as a protectant against stored grain pest infecting wheat seed. Ind. J. Entomol. 27, 161-167.

Larson, R.O., 1986. Development of margosan-O ${ }^{\circledR a}$ a pesticide from Neem seeds. Proc. $3^{\text {rd }}$ Int. Neem Conf., Nairobi, Kenya. pp. 245-250.

Matayo, D., 2002. The control of certain goat ectoparasites in Tanzania using Neem seed oil extract. PhD thesis, University of the Free State, South Africa.

Mersie, A. \& Bekele, M., 1994. Causes of hide damage in eastern Ethiopia. Wld. Anim. Rev. 79, 55-57.

Ngomuo, A.J. \& Kassuku, A.A., 1995. Gastrointestinal helminths and their seasonal occurrence in goats and sheep in Morogoro, Tanzania. Tan. Vet. J. 15, 1-9.

Norval, R.A.I., 1994. Aspects influencing the occurrence of infectious diseases in southern Africa. 1-Vectors: ticks. In: Infectious diseases of livestock with special reference to Southern Africa. Eds. Coetzer, J.A.W., Thompson, G.R. \& Trustin, R.C., Oxford University Press, Cape Town. pp. 3-24.

Norval, R.A.I., Sutherst, R.W., Kurki, J., Gibson, J.D. \& Kerr, J.D., 1988. The effect of the brown year tick Rhippicephalus appendiculatus on the growth of Sanga and European breeds of cattle. Vet. Parasitol. 30, 149-164.

Penzhorn B.L. \& Krecek, R.C., 1997. Veterinary parasitology in South Africa: Some highlights of the past 100 years. Vet. Parasitol. 71, 77-97.

Rembold, H., Forster, H. \& Czoppoelt, C.H., 1986. Structure and biological activity of Azadirachtins A and B. Proc. $3^{\text {rd }}$ Int. Neem Conf., Nairobi, Kenya. pp. 149-160.

Rocha, A., Starkey, P.H. \& Dionisio, A.C., 1990. Cattle production in Southern Mozambique. Agricultural Systems 37, 53-75.

SAS, 1992. Statistical Analysis Systems user's guide (6th ed.). SAS Institute Inc., Cary, North California.

Saxena, R.C., 1993. Scope of Neem for developing countries. Proc. World Neem Conf., 24-28 Febr., 1993, Bangalore, India. pp. 30-36.

Schumutterer, H., 1984. Neem research in the Federal Republic of Germany. Proc. $2^{\text {nd }}$ Int. Neem Conf. pp. 21-30.

Schumutterer, H., 1990. Properties and potential of natural pesticides from the Neem tree, Azadirachta indica. Ann. Rev. Entomol. 35, 271-279.

Spickett, A.M., De Klerk, D., Enslin, C.B. \& Scholtz, M.M., 1989. Resistance of Hereford, Bonsmara and Nguni cattle to ticks in a bushveld region of South Africa. Onderstepoort J. Vet. Res. 56, 245-250. 
(C) South African Society for Animal Science

Webb, E.C. \& David, M., 2002. The efficacy of Neem seed extract (Azadirachta indica) to control tick infestations in Tswana, Simmentaler and Brahman cattle. S. Afr. J. Anim. Sci. 32, 1-6.

Zebitz, C.P.W., 1986. Potential of Neem seed kernel extracts in mosquito control. Proc. $3^{\text {rd }}$ Int. Neem Conf., Nairobi, Kenya. pp. 555-573. 